\title{
Effects of co-occurring Wolbachia and Spiroplasma endosymbionts on the Drosophila immune response against insect pathogenic and non-pathogenic bacteria
}

Upasana Shokal ${ }^{1}$, Shruti Yadav ${ }^{1}$, Jaishri Atri ${ }^{1}$, Julia Accetta ${ }^{1}$, Eric Kenney ${ }^{1}$, Katherine Banks${ }^{1}$, Akash Katakam¹, John Jaenike ${ }^{2}$ and Ioannis Eleftherianos ${ }^{1 *}$

\begin{abstract}
Background: Symbiotic interactions between microbes and animals are common in nature. Symbiotic organisms are particularly common in insects and, in some cases, they may protect their hosts from pathogenic infections. Wolbachia and Spiroplasma endosymbionts naturally inhabit various insects including Drosophila melanogaster fruit flies. Therefore, this symbiotic association is considered an excellent model to investigate whether endosymbiotic bacteria participate in host immune processes against certain pathogens. Here we have investigated whether the presence of Wolbachia alone or together with Spiroplasma endosymbionts in D. melanogaster adult flies affects the immune response against the virulent insect pathogen Photorhabdus luminescens and against non-pathogenic Escherichia coli bacteria.

Results: We found that D. melanogaster flies carrying no endosymbionts, those carrying both Wolbachia and Spiroplasma, and those containing Wolbachia only had similar survival rates after infection with P. luminescens or Escherichia coli bacteria. However, flies carrying both endosymbionts or Wolbachia only contained higher numbers of $E$. coli cells at early time-points post infection than flies without endosymbiotic bacteria. Interestingly, flies containing Wolbachia only had lower titers of this endosymbiont upon infection with the pathogen $P$. luminescens than uninfected flies of the same strain. We further found that the presence of Wolbachia and Spiroplasma in D. melanogaster up-regulated certain immune-related genes upon infection with $P$. luminescens or $E$. coli bacteria, but it failed to alter the phagocytic ability of the flies toward E. coli inactive bioparticles.

Conclusion: Our results suggest that the presence of Wolbachia and Spiroplasma in D. melanogaster can modulate immune signaling against infection by certain insect pathogenic and non-pathogenic bacteria. Results from such studies are important for understanding the molecular basis of the interactions between endosymbiotic bacteria of insects and exogenous microbes.
\end{abstract}

Keywords: Drosophila melanogaster, Endosymbionts, Wolbachia, Spiroplasma, Insect pathogen, Photorhabdus luminescens, Infection, Innate immunity, Host-microbe interactions

\footnotetext{
* Correspondence: ioannise@gwu.edu

${ }^{1}$ Insect Infection and Immunity Lab, Department of Biological Sciences,

Institute for Biomedical Sciences, The George Washington University, 5675

Science and Engineering Hall, 800 22nd Street NW, Washington D.C. 20052,

USA

Full list of author information is available at the end of the article
} 


\section{Background}

The insect innate immune system includes a variety of defense mechanisms that individually or in tandem prevent foreign microoorganisms from invading the insect body or suppressing pathogen growth and proliferation $[1,2]$. The main insect defense mechanisms include the expression of antimicrobial peptides (AMP) by the fat body (equivalent to mammalian liver) into the hemolymph (equivalent to mammalian blood) [3], cellular responses by insect hemocytes (equivalent to mammalian white blood cells) [4], melanization and coagulation responses in the hemolymph [5], and generation of reactive oxygen species and nitric oxide in epithelial cells [6, 7]. These immune functions have been well characterized in the common fruit fly Drosophila melanogaster, which is an excellent model for studying the molecular and functional basis of the innate immune response $[8,9]$.

In addition to interactions with exogenous microbes, insects also interact with their endosymbiotic bacteria that are able to manipulate various physiological functions and the reproductive properties of their hosts [10]. Two of the most widespread and widely studied endosymbionts are Wolbachia and Spiroplasma, the first are carried by between $20 \%$ and $70 \%$ of all insect species [11, 12]. Wolbachia is a genus of maternally-transmitted, intracellular, Gram-negative, $\alpha$-proteobacteria which is known to induce parthenogenesis, male-killing, feminization, and cytoplasmic incompatibility (sperm-egg incompatibility) in their insect hosts $[13,14]$. Spiroplasma is a genus of wallless, motile, helical, Gram-positive bacteria which interact endo- and extracellularly with various insect species. Some strains of Spiroplasma can cause female-biased sex ratios through selective death of male offspring in their insect hosts [15]. Wolbachia and Spiroplasma have developed strategies to evade inherent insect host immune defenses in order to ensure survival and transmission and as a result, insect hosts have accordingly developed mechanisms to regulate endosymbiont populations to prevent fitness costs [16-19].

Although relationships between insects and their endosymbiotic bacteria have been studied most commonly with respect to nutritional effects on the host, recent studies have shown that some endosymbionts can protect their insect hosts from infections by certain pathogens [20]. Interestingly, D. melanogaster flies naturally contain Wolbachia and Spiroplasma endosymbionts, and they therefore constitute a convenient experimental model to investigate the impact of endosymbionts on the regulation of host immune function [12, 21]. Previous studies have shown that the presence of certain Wolbachia strains in D. melanogaster flies although it does not alter immune gene transcription [22], it can greatly enhance survival to infection by certain RNA viruses [23-31] and parasitoid wasps [32-34], but not to bacterial infections [35, 36].
The presence of Spiroplasma endosymbionts in D. melanogaster flies does not activate the immune system, but induction of Toll or immune deficiency (Imd) immune signaling increases Spiroplasma titer in the fly hemolymph. Also, D. melanogaster flies carrying Spiroplasma endosymbionts are more sensitive to some Gram-negative bacterial pathogens [37].

The Photorhabdus genus of entomopathogenic bacteria is a member of the Enterobacteriaceae family. In addition to being a highly virulent pathogen of insects, Photorhabdus maintains a mutualistic relationship with nematodes in the Heterorhabditidiae family [38]. $P$. luminescens bacteria are found in the gut of the infective juvenile (IJ) stage of the nematode Heterorhabditis bacteriophora [39]. The IJ stage is an obligate part of the nematode life-cycle that is required for infection of various insect species. Once inside the insect, the IJ regurgitates $P$. luminescens into the hemolymph where the bacteria begin to divide exponentially producing a wide range of toxins and hydrolytic enzymes that result in insect death within a few days [40]. Previous studies have shown that $P$. luminescens has evolved strategies for actively suppressing humoral and cellular immunity in infected insects to facilitate its successful replication and spread into the host [41].

The goal of this study was to investigate for the first time the participation of Wolbachia endosymbionts alone or in combination with Spiroplasma in the immune response of $D$. melanogaster adult flies against the virulent insect pathogen $P$. luminescens and a nonpathogenic strain of Escherichia coli. For this, we used D. melanogaster strains carrying different combinations of Wolbachia and Spiroplasma endosymbionts and found that although the survival response of flies with or without endosymbionts was unaffected upon infection with the pathogen $P$. luminescens or the non-pathogen $E$. coli, there were changes in bacterial load and endosymbiont titers in the infected flies. Interestingly, we further found significant induction of certain immune-related genes in flies carrying both endosymbionts following infection with the pathogenic or the non-pathogenic bacteria. This study shows that $D$. melanogaster and its endosymbiotic microbes form a particularly useful system to understand the impact of endosymbiosis on host immune activation and function against virulent pathogens as well as against non-pathogenic microorganisms.

\section{Methods}

\section{Fly strains}

D. melanogaster flies carrying both Wolbachia pipientis (strain wMel) and Spiroplasma poulsonii (strain MSRO) endosymbionts (designated as $\mathrm{W}+\mathrm{S}+$ ), no endosymbiotic bacteria (W-S-), or Wolbachia only (W+S-) were used in all experiments. All three types were derived 
from a single isofemale line collected in Uganda by John Pool. The original wild-caught female was infected with both endosymbionts $(\mathrm{W}+\mathrm{S}+)$; a sub-strain carrying only Wolbachia (W+S-) was obtained as a result of imperfect maternal transmission of Spiroplasma during lab culture; and a symbiont-free sub-strain (W-S-) was obtained by raising flies on medium containing tetracycline (final concentration of $0.25 \mathrm{mg} / \mathrm{mL}$ media) for one generations, followed by $>10$ generations of growth on tetracycline-free medium to allow recovery from tetracycline treatment. Because Spiroplasma is a male-killer [42], W + S+ strain produces a few or no males; so maintaining this strain entails mating its females to males from the W-S- strain every generation. All D. melanogaster strains were amplified for experimentation with approximately $2.5 \mathrm{~g}$ of Carolina Formula 4-24 Instant Drosophila media (Carolina Biological Supply), $10 \mathrm{~mL}$ of deionized water, and a dash (approximately $0.003 \mathrm{~g}$ ) of dry baker's yeast granules. All stocks were maintained at $25^{\circ} \mathrm{C}$ and a 12:12-h light:dark photoperiodic cycle. Adult female flies aged 7-10 day old were used in infection assays with bacteria.

\section{Endosymbiont status of fly strains}

Presence of endosymbionts in D. melanogaster strains was confirmed by performing diagnostic PCR on at least ten individual flies per strain. DNA from flies was isolated using DNeasy Blood \& Tissue Kit (Qiagen). PCR amplifications of Wolbachia and Spiroplasma sequences were performed using the following sets of primers: Wsp (Wolbachia), Forward: CATTGGTGTTGGTGTTGGTG and Reverse: AC CGAAATAACGAGCTCCAG [43]; and DnaA (Spiroplasma), Forward: TTAAGAGCAGTTTCAAAATCGGG and Reverse: TGAAAAAAACAAACAACAAATTGTTA TTACTTC [44] Each reaction was carried out in $50 \mu \mathrm{l}$ volume containing $20 \mu \mathrm{l}$ of 5-Prime Hot Master mix, $1 \mu \mathrm{l}$ each of forward and reverse primer $(10 \mu \mathrm{M}), 27 \mu \mathrm{l}$ of nuclease free water and $1 \mu \mathrm{l}$ of DNA (100-300 ng/ $\mu \mathrm{l})$. PCR amplifications were performed using a Bio-Rad T100 Thermal Cycler with the following cycling conditions: $94{ }^{\circ} \mathrm{C}$ for $2 \mathrm{~min}, 34$ cycles of $94{ }^{\circ} \mathrm{C}$ for $30 \mathrm{~s}, 59{ }^{\circ} \mathrm{C}$ (Wsp primers) or $56.7{ }^{\circ} \mathrm{C}$ (DnaA primers) for $1 \mathrm{~min}$ and $72{ }^{\circ} \mathrm{C}$ for $30 \mathrm{~s}$, and $72{ }^{\circ} \mathrm{C}$ for $5 \mathrm{~min}$. PCR control reactions for ribosopmal protein L32 (RpL32) gene were performed using the primers Rp49, Forward: GATGACCATCCGCC CAGCA and Reverse: CGGACCGACAGCTGCTTGGC with annealing temperature of $61{ }^{\circ} \mathrm{C}$ [45]. PCR samples were run on a $0.8 \%$ agarose gel DNA bands were visualized using a Molecular Image Chemidoc XRS (Bio-Rad).

\section{Bacterial strains}

The insect pathogenic bacterium $P$. luminescens subsp. laumondii (strain TT01) and the non-pathogenic bacterium Escherichia coli (strain K12) were used for fly infections.
Bacterial cultures $(10 \mathrm{ml})$ were prepared in sterile LuriaBertani (LB) broth and grown for approximately $18-24 \mathrm{~h}$ at $30{ }^{\circ} \mathrm{C}$ on a rotary shaker at $280 \mathrm{rpm}$. Bacterial cultures were centrifuged at $885 \mathrm{~g}$ or $3,000 \mathrm{rpm}$ and $4{ }^{\circ} \mathrm{C}$ for $5 \mathrm{~min}$ and the resulting bacterial pellets were washed and resuspended in $1 \mathrm{X}$ sterile phosphate-buffered saline (PBS, Sigma Aldrich). Bacterial cell concentration of the final solution was analyzed using a spectrophotometer (NanoDropTM 2000c - Thermo Fisher Scientific), and concentration was adjusted to Optical Density $(260 \mathrm{~nm})$ of 0.1 , for P. luminescens and 0.015 for E. coli.

\section{Fly survival}

Fly infections were carried out by injection of $18.4 \mathrm{nl}$ of a bacterial suspension (P. luminescens or E. coli) using a Nanoject II apparatus (Drummond Scientific) equipped with glass capillaries prepared with the use of a Micropipette Puller (Sutter Instruments). Flies were handled using a stereomicroscope outfitted with lights and the Ultimate Flypad (Flystuff). Injections were performed into the thorax of 7-10 day old adult flies that were previously anesthetized briefly with carbon dioxide. Injection of the same volume of PBS was used as a control. After infections, flies from each $D$. melanogaster strain were transferred to fresh vials with instant media at $25^{\circ}$ $\mathrm{C}$ and survival was scored at 6-h intervals and up to 1 day. Two replicates of ten flies were used for each treatment and each assay was replicated three times.

\section{Cloning of plasmid DNA and generation of standard curves}

DNA from Wolbachia and Spiroplasma was extracted from 7-10 day old uninfected $\mathrm{W}+\mathrm{S}+$ flies. DNA from $E$. coli and P. luminescens was extracted from bacterial overnight cultures. DNA samples were isolated using the Dneasy Blood and Tissue kit (Qiagen) and PCR amplifications were performed using the primers Mcf-1 (P. luminescens), Forward: TTGGCGGGGTGGTAGTCG and Reverse: CAGTTCAGCTTCCTTCTCTAA; 16S rRNA (E. coli), Forward: GGAAGAAGCTTGCTTCTTTGCTG AC and Reverse: AGCCCGGGGATTTCACATCTGAC TTA; as well as Wsp and DnaA primers with the mix conditions that were described above. PCR amplifications for $M c f-1$ and $16 s$ rRNA sequences were performed using the following cycling conditions: $94{ }^{\circ} \mathrm{C}$ for $2 \mathrm{~min}, 34$ cycles of $94{ }^{\circ} \mathrm{C}$ for $30 \mathrm{~s}, 61{ }^{\circ} \mathrm{C}$ for $1 \mathrm{~min}$ and $72{ }^{\circ} \mathrm{C}$ for $30 \mathrm{~s}$, and $72{ }^{\circ} \mathrm{C}$ for $5 \mathrm{~min}$. The PCR products were cloned into Strataclone cloning vector (Agilent Technologies) and $E$. coli competent cells were transformed and then grown overnight in LB broth at $37^{\circ} \mathrm{C}$. Plasmids were isolated using GenElute ${ }^{\mathrm{Tm}}$ Plasmid Miniprep Kit (Sigma Aldrich) and then eluted in $40 \mu \mathrm{l}$ of nuclease-free water. Dilutions were made for each plasmid to generate the standard curves. The reactions contained $5 \mu$ l of the diluted 
plasmid with $10 \mu \mathrm{l}$ of $\mathrm{SYBR}^{\circ}$ GreenER with Premixed ROX (Invitrogen), $4.2 \mu \mathrm{l}$ of nuclease free water and 10 pmol of each forward and reverse primer. The generated standard curves were used for estimating bacterial load (Colony Forming Units, CFU) and endosymbiont titers.

\section{Bacterial load and endosymbiont titers}

Five adult flies from each strain were injected with $E$. coli, P. luminescens, or $1 \mathrm{x}$ sterile PBS (septic-injury control), and then frozen at 0,6 and $18 \mathrm{~h}$ post infection. DNA samples were eluted in $40 \mu \mathrm{l}$ of elution buffer and concentrations were measured using a NanoDrop. Each PCR reaction included $10 \mu \mathrm{l}$ of EXPRESS SYBR $^{\circ}$ GreenER with Premixed ROX (Invitrogen), $10 \mu \mathrm{M}$ of each forward and reverse primer sets (Mcf-1, 16 s rRNA, Wsp and DnaA) and 350 ng of each DNA sample. Cycling conditions for estimating $E$. coli and P. luminescens load were $50{ }^{\circ} \mathrm{C}$ for $2 \mathrm{~min}, 95{ }^{\circ} \mathrm{C}$ for $2 \mathrm{~min}, 40$ cycles of $95{ }^{\circ} \mathrm{C}$ for $15 \mathrm{~s}$ and an annealing step of $61{ }^{\circ} \mathrm{C}$ for $15 \mathrm{~s}$. Cycling conditions for estimating Spiroplasma titers were the same except for the annealing step which was $56.7{ }^{\circ} \mathrm{C}$. For estimating Wolbachia titers, cycling conditions were $50{ }^{\circ} \mathrm{C}$ for $2 \mathrm{~min}, 95{ }^{\circ} \mathrm{C}$ for $10 \mathrm{~min}, 40$ cycles of $95{ }^{\circ} \mathrm{C}$ for $30 \mathrm{~s}, 59^{\circ} \mathrm{C}$ for $1 \mathrm{~min}$, and $72{ }^{\circ} \mathrm{C}$ for $30 \mathrm{~s}$. All samples were run in duplicates and the experiments were repeated three times.

\section{Gene trascription}

Four adult flies from each strain were injected with $P$. luminescens TT01, E. coli $\mathrm{K} 12$ or PBS, and frozen at 0 , 6 , and $18 \mathrm{~h}$ after infection. Total RNA was extracted using the PrepEase RNA spin kit (Affymetrix USB) and samples were suspended in $40 \mu \mathrm{L}$ of sterile nuclease-free water. Complementary DNA (cDNA) synthesis was carried out using the High Capacity cDNA Reverse Transcription Kit (Applied Biosystems, USA), $1 \mu \mathrm{l}$ of Recombinant RNasin ${ }^{\circ}$ Ribonuclease Inhibitor (Promega, USA) and 140 ng of RNA sample as starting material in a total reaction volume of $20 \mu \mathrm{l}$. PCR cycles included $25{ }^{\circ} \mathrm{C}$ for $10 \mathrm{~min}, 37^{\circ} \mathrm{C}$ for $2 \mathrm{~h}$, and $85^{\circ} \mathrm{C}$ for $5 \mathrm{~min}$. Resulting cDNA samples were diluted 1:10 in nucleasefree water and $1 \mu \mathrm{l}$ was used as a template for quantitative RT-PCR experiments using the EXPRESS SYBR ${ }^{\circ}$ GreenER kit with Premixed ROX (Invitrogen) on a Mastercycler ${ }^{\circ}$ ep realplex ${ }^{2}$ (Eppendorf). The reactions were carried out in a total reaction volume of $20 \mu \mathrm{l}$ and technical duplicates were run for each sample and set of primers (Table 1). The cycling program was: $50{ }^{\circ} \mathrm{C}$ for 2 min, $95{ }^{\circ} \mathrm{C}$ for $2 \mathrm{~min}, 40$ cycles of $95{ }^{\circ} \mathrm{C}$ for $15 \mathrm{~s}$ and an annealing step for $15 \mathrm{~s}$. For each sample, the amount of mRNA detected was normalized to mRNA values of the control housekeeping gene $R p L 32$. Normalized data were used to quantify the relative level of a given mRNA according to cycling threshold analysis $(\Delta \mathrm{Ct})$, and the
Table 1 Primers used for qRT-PCR analysis

\begin{tabular}{lllll}
\hline Gene & $\begin{array}{l}\text { Accession } \\
\text { No }\end{array}$ & Primer & Sequence & Tm $\left({ }^{\circ} \mathrm{C}\right)$ \\
\hline Cecropin-A1 & CG1365 & Forward & TCTTCGTTTCGTCGCTCTC & 60 \\
& & Reverse & CTTGTGAGCGATCCCAGT & \\
Defensin & CG1385 & Forward & CGCATAGAAGCGAGCCACATG & 56 \\
& & Reverse & GCAGTAGCCGCCTTGAACC & \\
TurandotM CG14027 & Forward & GCTGGGAAGGTAAATGCTG & 61 \\
& & Reverse & AGGCGCTGTTTTCTGTGAC & \\
Puckered & CG7850 & Forward & GGCCTACAAGCTGGTGAAG & 61 \\
& & Reverse & AGTTCAGATTGGGGAGATG & \\
RpL32 & CG7939 & Forward & GATGACCATCCGCCCAGCA & 61 \\
& & Reverse & CGGACCGACAGCTGCTTGGC & \\
\hline
\end{tabular}

All sequences read $5^{\prime}$ to $3^{\prime}$ left to right

data were expressed as the ratio of $2^{\mathrm{CT}(\mathrm{RpL} 32)} / 2^{\mathrm{CT}(\text { gene) }}$. Data are presented as the ratio of infected flies to PBS injected flies (negative controls for bacterial infections). Results represent the mean values and standard deviations of relative values from three biological repetitions.

\section{Hemocyte phagocytosis}

Adult flies were injected in the abdomen with $15.6 \mathrm{nl}$ of $1 \mathrm{mg} / \mathrm{ml}$ lipophilized pHrodo-labeled E. coli particles (Molecular Probes, P35361) reconstituted in $1 \mathrm{ml}$ sterile, Diethylpyrocarbonate (DEPC) treated water. Injected flies were then affixed dorsally/wing side down to a glass microscope slide using clear nail polish and living flies were observed at 30,45 , and 60 min post infection using a fluorescent microscope outfitted with a pHrodo red filter at 10x magnification. Resulting images were processed using ImageJ software and background fluorescence was measured. Relative amounts of fluorescence were measured by applying Shanbhag thresholding to images and measuring the resulting area, mean fluorescence of background and integrated density. Corrected total fluorescence was determined using the following equation: Corrected total fluorescence $=$ Integrated Density (Area * Mean fluorescence of background). Data were statistically analyzed via GraphPad Prism5 software and the Chi square test. Each experiment was repeated three times with 6-12 flies per treatment.

\section{Statistical analysis}

Statistics were performed using the GraphPad Prism5 software. Statistical analysis of data from survival experiments was conducted using a log-rank (Mantel-Cox) and $C h i$ square tests. $P$ values below 0.05 were considered statistically significant. Unpaired two-tailed $t$-test was performed for analyzing bacterial load and endosymbiont titers. Means were compared using a one-way analysis of variance (ANOVA) with a Tukey post-hoc 
test for multiple comparisons. All figures were also generated using GraphPad Prism5 software.

\section{Results \\ Presence of Wolbachia and Spiroplasma in D. melanogaster strains}

We used PCR to document the presence of Wolbachia and Spiroplasma in the three D. melanogater strains used in our experiments (Fig. 1). We used gene-specific primers to amplify nucleotide sequences of the gene coding for the Wolbachia surface protein (Wsp) (160 bp) [43], and the Spiroplasma gene DnaA (138 bp) [44]. We also performed PCR control reactions to amplify a $360 \mathrm{bp}$ fragment of the D. melanogaster housekeeping gene RpL32 [45]. We confirmed that one $D$. melanogaster strain contained both Wolbachia and Spiroplasma endosymbionts $(\mathrm{W}+\mathrm{S}+)$, one strain contained Wolbachia bacteria only (W+S-), and one strain contained no endosymbiotic bacteria (W-S-).

\section{Wolbachia and Spiroplasma do not affect the survival} response of $D$. melanogaster to $P$. luminescens infection We initially investigated the survival response of $D$. melanogaster flies carrying or lacking endosymbionts to infection by $P$. luminescens bacteria. We also performed injections with non-pathogenic $E$. coli and PBS buffer (Fig. 2). For flies injected with either E. coli or PBS, survival at the 24-h time-point was very high and not affected by the endosymbiont status of the flies $(\mathrm{W}+\mathrm{S}+$, $\mathrm{W}+\mathrm{S}-$, or $\mathrm{W}-\mathrm{S}-$; log-rank test, $P>0.05$ in both cases; Fig. $2 \mathrm{a}$ and $\mathrm{b})$. Infection with the insect pathogenic bacterium $P$. luminescens resulted in death of all strains within $24 \mathrm{~h}$, but again, there was no significant effect of the endosymbionts on fly survival (log-rank test, $P>$ 0.05 ; Fig. 2c). These results show that the presence of Wolbachia alone or together with Spiroplasma in D. melanogaster does not affect survival of the flies in

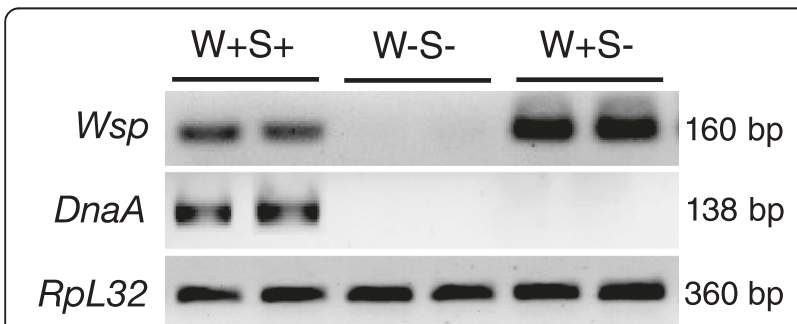

Fig. 1 PCR diagnostic for the presence or absence of endosymbionts in D. melanogaster strains. Amplification of Wsp and DnaA gene sequences from 7-10 day old flies carrying both Wolbachia and Spiroplasma $(\mathrm{W}+\mathrm{S}+$ ), flies lacking both endosymbionts $(\mathrm{W}-\mathrm{S}-)$, and flies carrying Wolbachia only ( $\mathrm{W}+\mathrm{S}-$ ). The sizes of the PCR products are indicated. Two replicate experiments (different flies) are shown for each D. melanogaster strain. PCR amplification of the constitutively expressed gene RpL32 is used as loading control response to infection with either non-pathogenic $E$. coli bacteria nor the entomopathogen $P$. luminescens.

Presence of endosymbionts can alter bacterial load in $D$. melanogaster following infection with non-pathogenic bacteria

To examine changes in bacterial load following infection with a non-pathogenic strain of $E$. coli, we injected $E$. coli $\mathrm{K} 12$ cells into $\mathrm{W}+\mathrm{S}+, \mathrm{W}+\mathrm{S}$-, and $\mathrm{W}-\mathrm{S}$ - adult flies and estimated number of CFU at 6 and $18 \mathrm{~h}$ post infection. We found that at $6 \mathrm{~h}$ there were signifIcantly higher numbers of $E$. coli cells in $\mathrm{W}+\mathrm{S}+$ and $\mathrm{W}+\mathrm{S}$ flies than in W-S- flies $(P<0.05$, Fig. 3a), although there were no significant differences in $E$. coli numbers among the different strains at 0 and $18 \mathrm{~h}$ time-points $(P>0.05$, Fig. 3a).

We then tested whether infection with non-pathogenic E. coli bacteria affects the number of Wolbachia and Spiroplasma endosymbionts in D. melanogaster flies. Using the same samples and a PCR approach, we found no significant differences in Wolbachia numbers between the E. coli infected strains and the PBS injected controls for any of the time-points used in the experiments $(P>0.05$, Fig. 3b). We also estimated Spiroplasma numbers in $\mathrm{W}+\mathrm{S}+$ flies injected with $\mathrm{PBS}$ buffer or non-pathogenic $E$. coli bacteria, and we found no significant changes at any time-point $(P>0.05$, Fig. $3 c)$.

Presence of endosymbionts does not alter bacterial load in $D$. melanogaster following $P$. luminescens infection

To test whether the presence of Wolbachia and Spiroplasma in D. melanogaster affects replication of insect pathogenic bacteria, we injected adult flies with $P$. luminescens and monitored bacterial load at two time-points post infection. Although we found that P. luminescens CFU increased steadily at 6 and $18 \mathrm{~h}$ post infection, there were no significant differences in $P$. luminescens numbers among the $\mathrm{W}+\mathrm{S}+, \mathrm{W}+\mathrm{S}-$, and $\mathrm{W}-\mathrm{S}$ - fly strains ( $P>0.05$, Fig. 4a). We also evaluated numbers of Wolbachia endosymbionts in $P$. luminescens infected flies and PBS injected flies and found that at $18 \mathrm{~h}$ post injection, $\mathrm{W}+\mathrm{S}$ - flies contained significantly higher numbers of Wolbachia than the uninfected controls $(P<0.05$, Fig. $4 \mathrm{~b})$. However, there were no significant changes in Spiroplasma numbers in the $\mathrm{W}+\mathrm{S}+$ strain upon injection with PBS or the pathogenic bacteria $(P>0.05$, Fig. $4 c)$.

Changes in immune gene transcription in $D$. melanogaster flies carrying Wolbachia and Spiroplasma upon bacterial infection

An important aspect of the innate immune system of $D$. melanogaster is the transcriptional induction of AMP genes in response to bacterial infections. The Imd pathway is activated by diaminopimelic acid (DAP)-type peptidoglycan 

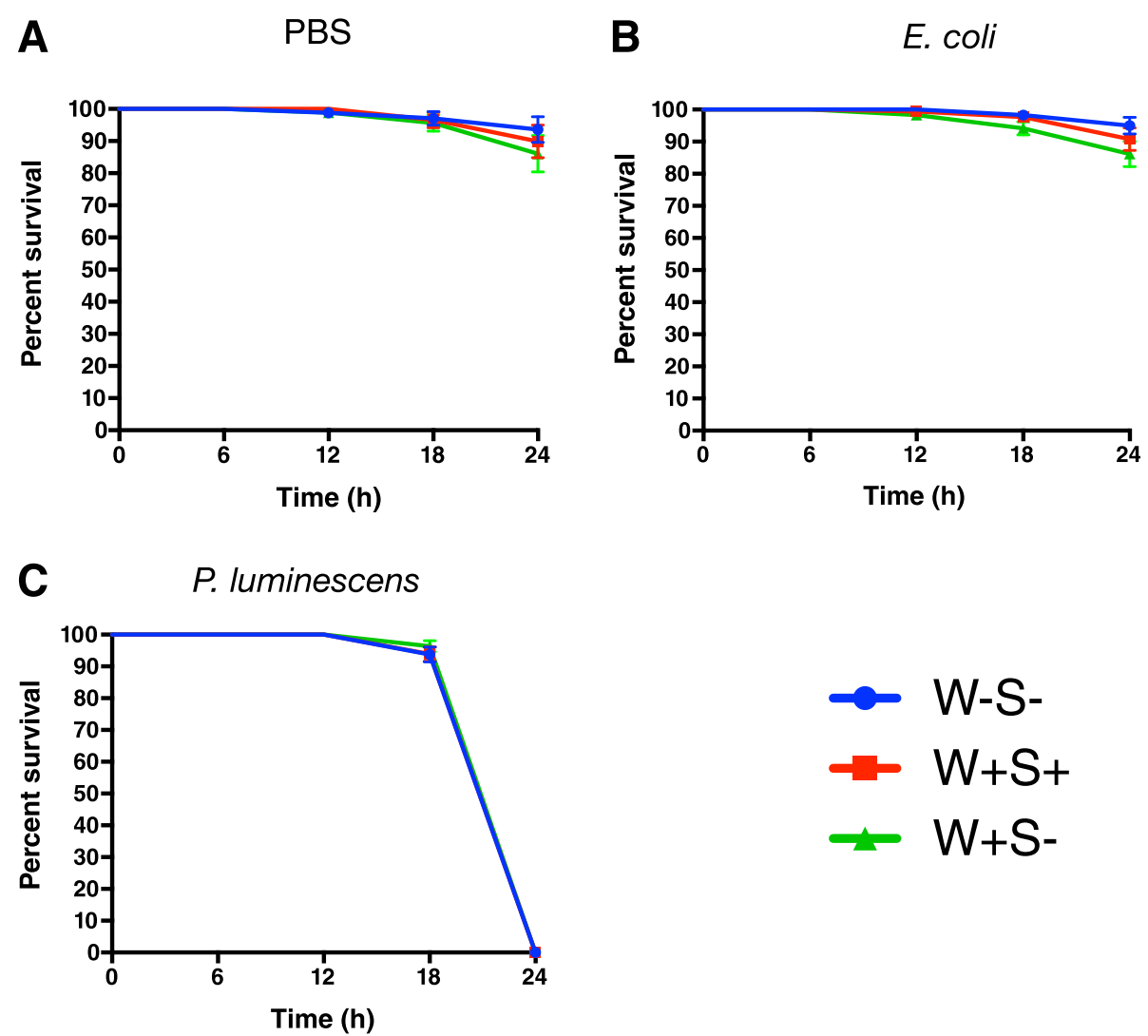

Fig. 2 Survival of D. melanogaster flies carrying or lacking endosymbionts following bacterial infection. Survival of 7-10 day old flies lacking Wolbachia and Spiroplasma (W-S-), flies carrying both endosymbionts (W + S+), and flies carrying Wolbachia only (W + S-) following intrathoracic injection with (a) sterile PBS (septic injury control), (b) E. coli bacteria (strain K12), or (c) P. luminescens bacteria (strain TT01). Survival was monitored for $24 \mathrm{~h}$ at 6-h intervals. Data analysis was performed using Log-Rank test (GraphPad Prism5 software) and the values are the percent survival of the infected flies. The means from three independent experiments are shown and bars represent standard errors

that is found in all Gram-negative and certain Grampositive bacteria, while the Toll pathway is activated by Lystype peptidoglycan found in most other Gram-positive bacteria [46]. Here we used qRT-PCR to determine the induction of immune signaling pathways in Drosophila strains carrying or lacking endosymbionts at the time of injection with $E$. coli or P. luminescens and at two timepoints post bacterial infection (Fig. 5). For this, we used gene-specific primers to estimate the transcription of Cecropin-A1 as a readout for the Imd pathway, Defensin for the Toll pathway, Turandot $M($ TotM) for the Janus kinase and signal transducer and activator of transcription (Jak/Stat) pathway and Puckered for the c-Jun N-terminal kinase (JNK) pathway [47-50]. The non-pathogenic bacteria $E$. coli altered gene transcription in all three D. melanogaster strains compared to uninfected controls (Fig. 5a, c, e, g). We also found that transcription of Defensin in flies containing Wolbachia and Spiroplasma was significantly higher at $18 \mathrm{~h}$ post-infection compared to the $0 \mathrm{~h}$ time-point $(P<0.05$, Fig. 5c). However, Defensin transcription was significantly higher in flies containing both endosymbionts compared to those containing
Wolbachia only at $18 \mathrm{~h}$ post infection $(P<0.05$, Fig. $5 \mathrm{c})$. For gene transcription in flies infected with the pathogen $P$. luminescens, we found that Cecropin-A1 transcription significantly increased at $18 \mathrm{~h}$ post infection in flies lacking endosymbionts $(P<0.01$, Fig. $5 \mathrm{~b})$ and in those containing both Wolbachia and Spiroplasma $(P<0.0001$, Fig. $5 \mathrm{~b})$. Also, at $18 \mathrm{~h}$ post infection with $P$. luminescens, flies carrying both endosymbionts showed significantly stronger Cecropin-A1 transcription compared to those containing Wolbachia only $(P<0.0001$, Fig. 5b). TotM transcription in flies carrying both endosymbionts was significantly higher at $6 \mathrm{~h}$ post infection with $P$. luminescens compared to the other two time-points $(P<0.05$, Fig. 5f). In addition, Tot $M$ transcription was significantly higher in flies containing both Wolbachia and Spiroplasma compared to flies containing Wolbachia only or no endosymbionts at $6 \mathrm{~h}$ post-infection $(P<0.05$, Fig. $5 f)$. There were no significant differences in Defensin and Puckered gene transcription between the three fly strains following infection with $P$. luminescens bacteria at any of the time-points tested in this study $(P>0.05$, Fig. $5 b, d, h)$. These results suggest that the presence of both Wolbachia and 

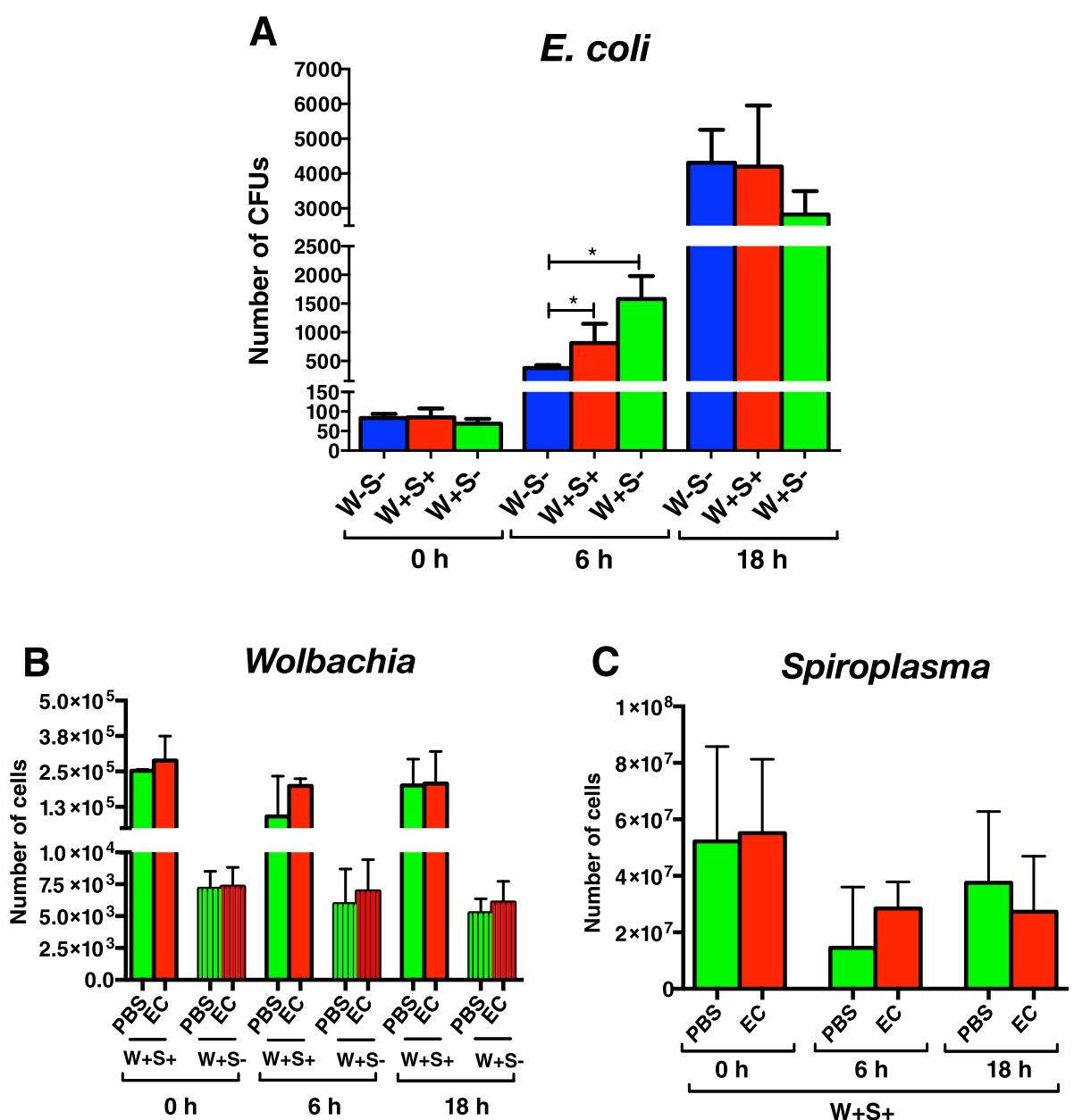

Fig. 3 E. coli load and endosymbiont titers in infected D. melanogaster flies carrying or lacking endosymbionts. E. coli bacteria (strain K12) or 1X sterile PBS were injected into D. melanogaster flies lacking Wolbachia and Spiroplasma (W-S-), flies carrying both endosymbionts (W + S+), and flies carrying Wolbachia only (W + S-). a Colony Forming Units (CFUs) for E. coli, (b) number of cells for Wolbachia, and (c) number of cells for Spiroplasma at 0, 6 and $18 \mathrm{~h}$ after infection were determined by quantitative PCR. Data analysis was performed by unpaired two-tailed $t$-test and significant differences are indicated by an asterisk $\left({ }^{*} P<0.05\right)$. Bars show the means from three independent experiments and error bars represent standard deviations

Spiroplasma endosymbionts in D. melanogaster flies can alter the transcription of certain immune-related genes following infection with non-pathogenic bacteria or the insect-specific pathogen P. luminescens.

\section{Wolbachia and Spiroplasma do not alter phagocytosis in D. melanogaster}

We estimated phagocytic ingestion in D. melanogaster strains carrying or lacking endosymbionts by injecting inactivated unopsonized fluorogenic $E$. coli particles into adult flies and using fluorescence microscopy (Fig. 6a). We found that phagocytosis of $E$. coli particles in $D$. melanogaster flies was not significantly affected by the presence of Wolbachia endosymbionts alone or in combination with Spiroplasma endosymbionts at any timepoint after injection of the fluorescent particles $(P>0.5$, Fig. 6b). However, we noticed that regardless of whether flies contained Wolbachia only or both Wolbachia and Spiroplasma, phagocytosis levels were significantly higher ( $\mathrm{P}$ values ranged from $<0.1$ to $<0.0001$ ) at $30 \mathrm{~min}$ after injection of the E. coli particles compared to the 45 and $60 \mathrm{~min}$ time-points. These results support the notion that Wolbachia and Spiroplasma endosymbionts do not affect the phagocytic function of $D$. melanogaster adult flies.

\section{Discussion}

Recent studies have examined the involvement of endosymbiotic bacteria in the immune response of different Drosophila species against infections by various bacterial pathogens [35-37]; however, here we investigated for the first time changes in immune signalling and function in D. melanogaster flies against the virulent insect-specific pathogen $P$. luminescens. These bacteria are known to 

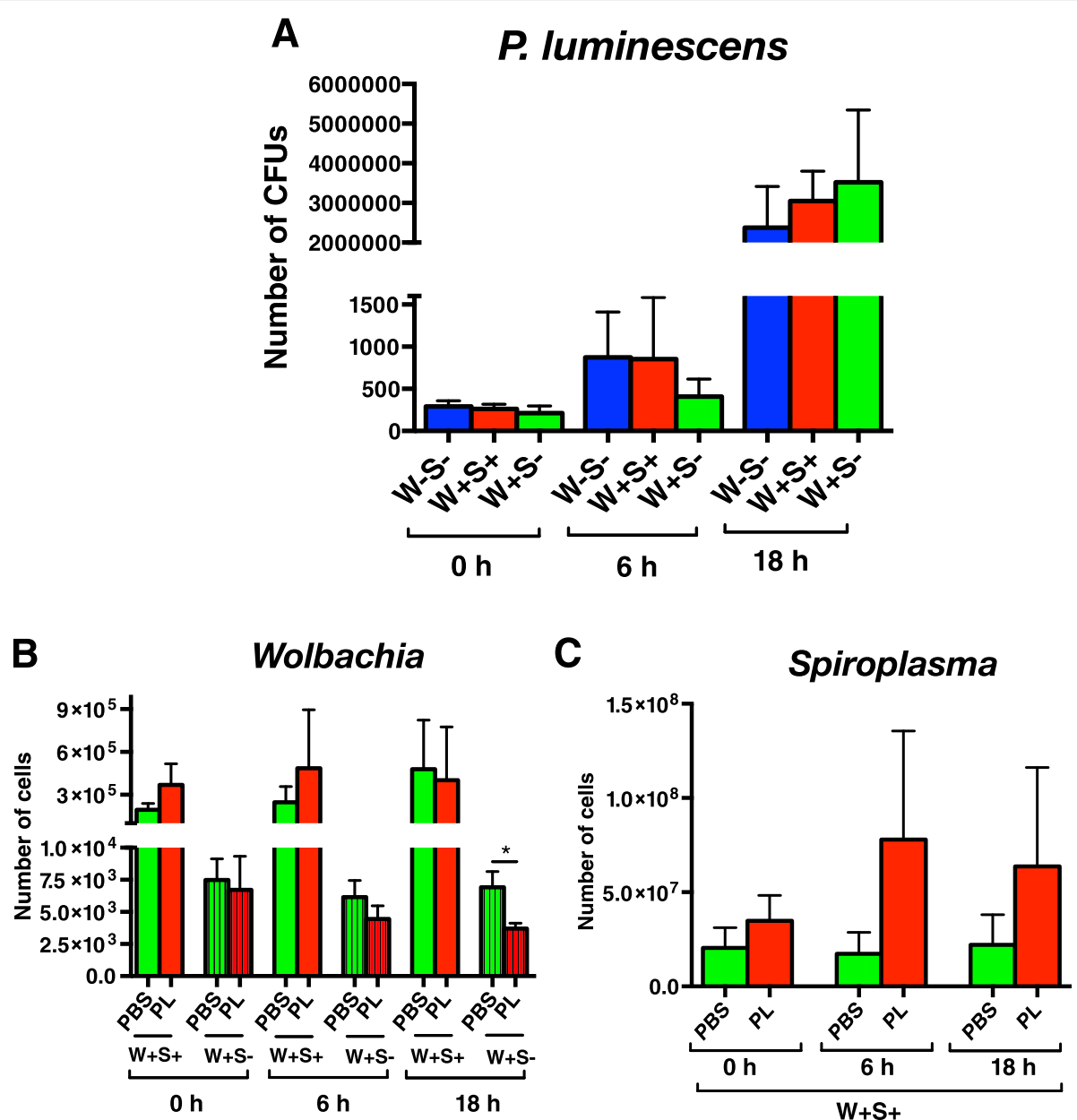

Fig. 4 P. luminescens load and endosymbiont titers in infected D. melanogaster flies carrying or lacking endosymbionts. P. luminescens pathogenic bacteria (strain TT01) or 1X sterile PBS were injected into D. melanogaster adult flies lacking Wolbachia and Spiroplasma (W-S-), flies carrying both endosymbionts $(\mathrm{W}+\mathrm{S}+$ ), and flies carrying Wolbachia only (W+S-). a Colony Forming Units (CFUs) for P. luminescens, (b) number of cells for Wolbachia, and (c) number of cells for Spiroplasma at 0,6 and $18 \mathrm{~h}$ after infection were determined by quantitative PCR. Data analysis was performed by unpaired two-tailed $t$-test and significant differences are indicated by an asterisk $\left({ }^{*} P<0.05\right)$. Bars show the means from three independent experiments and error bars represent standard deviations

be extremely pathogenic to a wide range of insect species because they can secrete a vast array of toxins and they can employ mechanisms to disarm the insect immune system [38, 41]. Current survival results are in agreement with recent findings reporting that D. melanogaster flies carrying or lacking Wolbachia endosymbionts were able to survive similarly upon infection with the Gram-negative bacteria Pseudomonas aeruginosa, Serratia marcescens, and Erwinia carotovora [35]; however, D. melanogaster flies carrying a naturally occurring strain of Spiroplasma and without the presence of other ensosymbionts proved more sensitive to the Gram-negative pathogens E. carotovora and Enterobacter cloacae, but not to the Gram-positive pathogen Enterococcus faecalis [37].

Although Wolbachia alone or in combination with Spiroplasma endosymbionts failed to provide protection to $D$. melanogaster against $P$. luminescens infection, we investigated whether the pathogens replicated at similar or different rates in the three fly strains and whether differential replication of these bacteria would affect endosymbiont titers in the infected flies. We were unable to find changes in P. luminescens load among the different strains, which shows that Wolbachia does not influence the growth of this pathogen in the fly. Previous studies have also failed to find significant differences in pathogen load between fly strains carrying or lacking Wolbachia endosymbionts [35-37]. Our data also suggest that the presence of Spiroplasma in D. melanogaster in addition to Wolbachia endosymbionts does not affect the replication of $P$. luminescens and therefore the presence of those endosymbiotic microbes in the fly is not essential for altering the growth of this pathogen. Strikingly, there was a drop in Wolbachia titers in flies carrying those endosymbionts alone after infection with $P$. luminescens, 


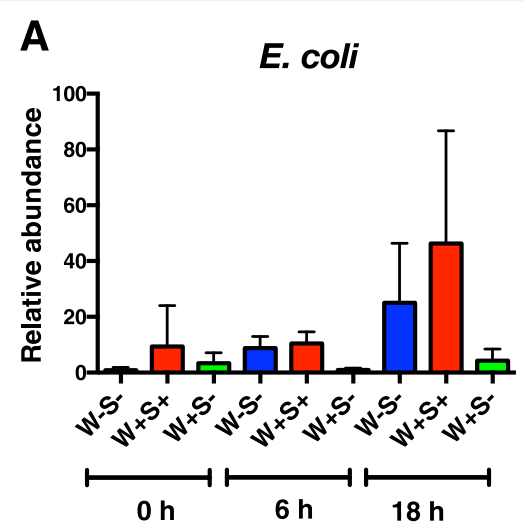

B
$P$. luminescens

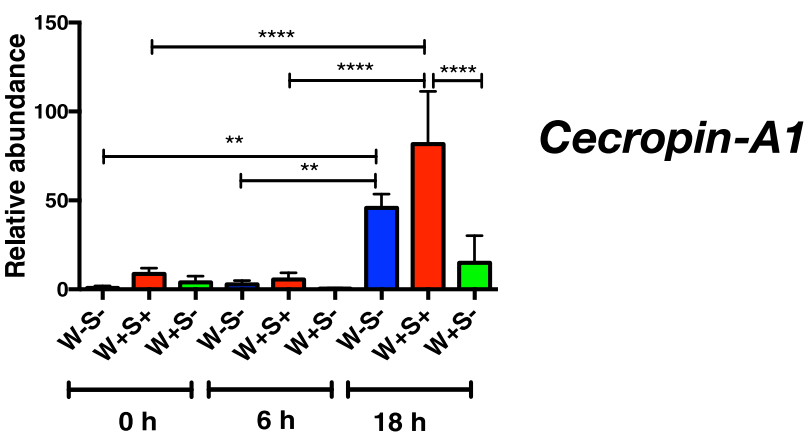

C

E. coli

D
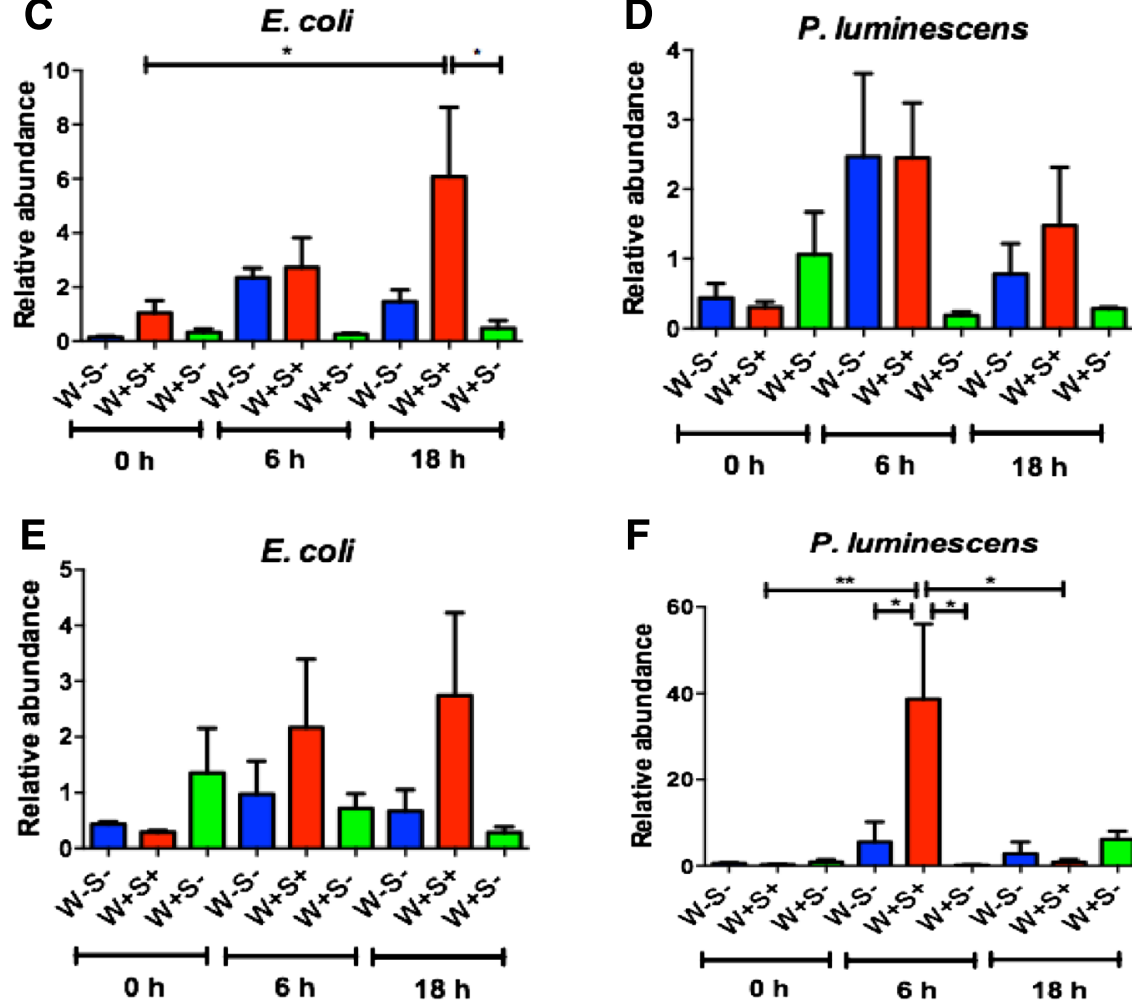

F

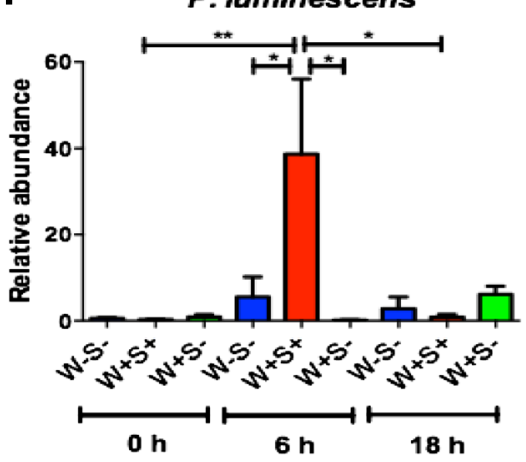

Defensin

G

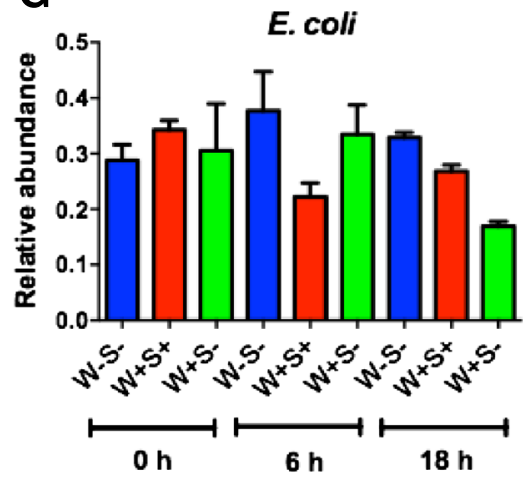

H

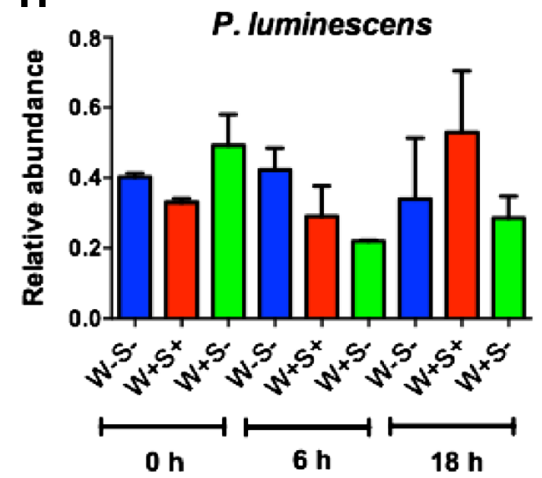

TotM

\section{Puckered}

Fig. 5 (See legend on next page.) 
(See figure on previous page.)

Fig. 5 Transcription of immune signaling pathway genes in flies carrying or lacking endosymbionts following bacterial infection. Gene transcription levels for Cecropin-A1 $(\mathbf{a}, \mathbf{b})$, Defensin $(\mathbf{c}, \mathbf{d})$, Turandot (Tot) $M(\mathbf{e}, \mathbf{f})$ and Puckered $(\mathbf{g}, \mathbf{h})$ in D. melanogaster adult flies without Wolbachia and Spiroplasma (W-S-), with both endosymbionts (W+S+), and with Wolbachia only (W+S-) at 0, 6 and $18 \mathrm{~h}$ after infection with $E$. coli (strain K12) or P. luminescens (strain TT01). Gene transcription levels are shown as relative abundance of transcripts normalized to gene RpL32 and expressed as a ratio compared to flies injected with sterile PBS (negative control). Values represent the means from three biological replicates and error bars represent standard deviations. ${ }^{* * *} P<0.0001 ;{ }^{* *} P<0.01 ;{ }^{*} P<0.05$ (one way analysis of variance with a Tukey post hoc test, GraphPad Prism5 software)

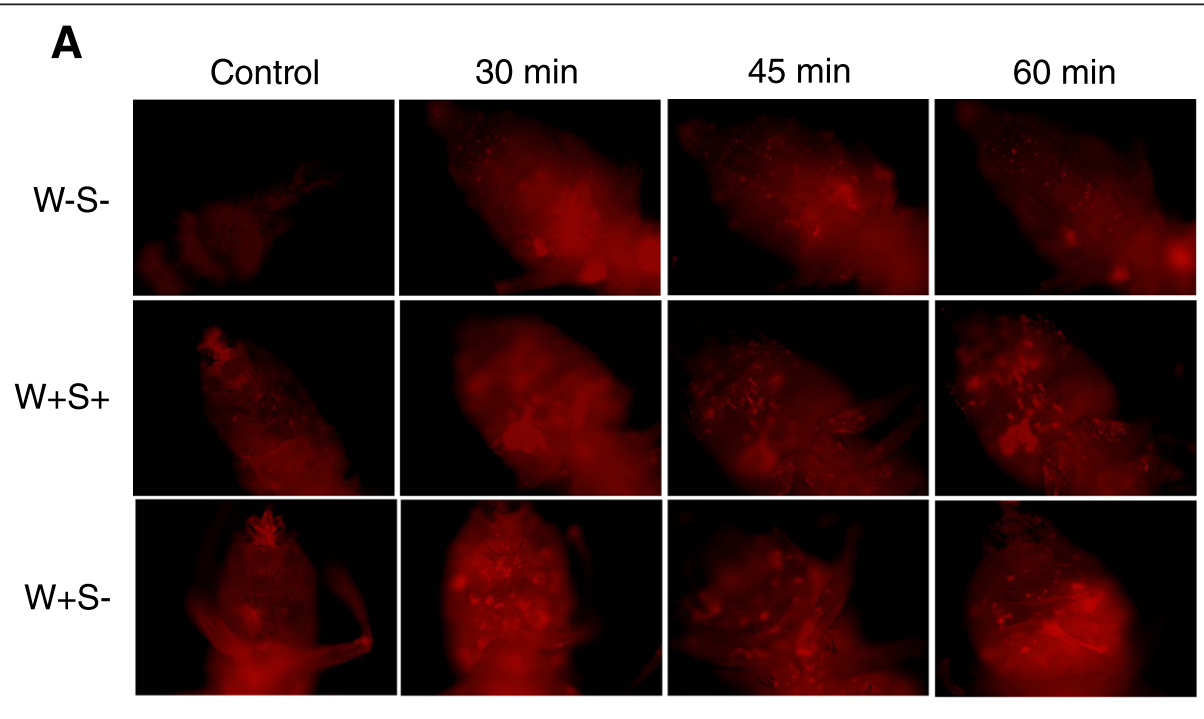

B

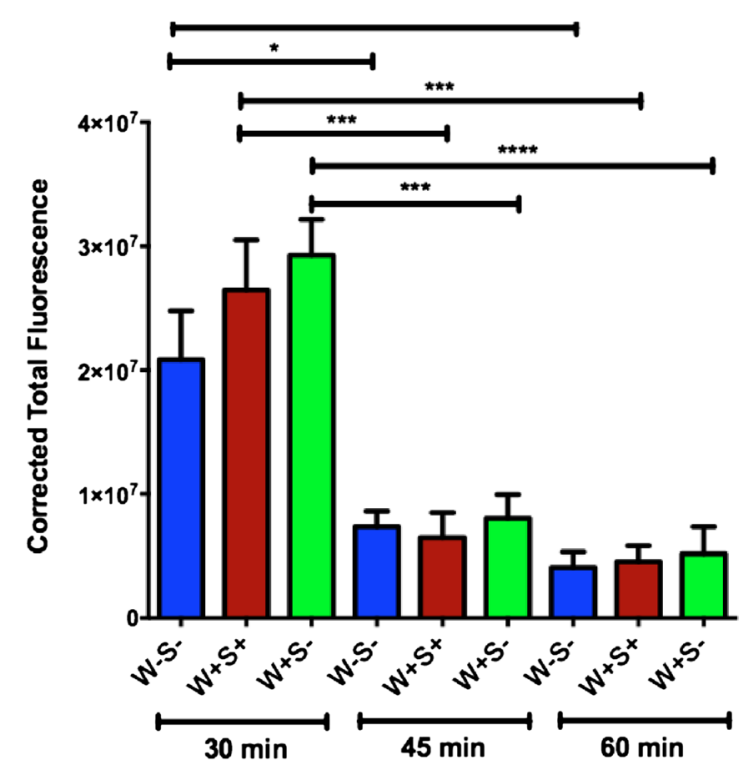

Fig. 6 Phagocytosis in D. melanogaster flies carrying or lacking endosymbiotic bacteria. a Representative images of phagocytosis in $D$. melanogaster adult flies without Wolbachia and Spiroplasma (W-S-), with both endosymbionts (W + S+), and with Wolbachia only (W + S-) at 30, 45 and 60 min after injection of lipophilized pHrodo-labeled E. coli particles. Control treatments involved injections with DEPC-treated water. Images were taken using fluorescence microscopy and 10x magnification. b Corrected total fluorescence in the three D. melanogaster flies at 30, 45 and 60 min following injection of pHrodo-labeled E. coli. Images were processed in ImageJ and corrected total fluorescence was estimated by measuring relative amounts of fluorescence, which included estimations of the resulting area, mean fluorescence of background and integrated density. The experiment was repeated three times with 6-12 flies for each treatment. ${ }^{* * *} P<0.0001 ;{ }^{* * *} P<0.001$; ${ }^{* *} P<0.01$; ${ }^{*} P<0.05$ (one way analysis of variance with a Tukey post hoc test, GraphPad Prism5 software) 
which could imply that these endosymbiotic bacteria can be directly or indirectly targeted by the pathogen.

Reduced numbers of $E$. coli cells in flies with no endosymbionts compared to flies containing both endosymbionts or Wolbachia only at early times after infection indicates that the absence of endosymbiotic bacteria may control more efficiently the early stages of an infection by non-pathogenic bacteria. Alternatively, the presence of endosymbionts in the fly could provide a favorable environment that could promote the early replication of exogenous non-pathogenic bacteria, which do not affect insect survival and they are ultimately cleared by the fly immne system [51]. The increase in E. coli numbers in flies containing endosymbiotic bacteria at $6 \mathrm{~h}$ post infection is not accompanied by changes in the numbers of Wolbachia cells. These results imply that although the existence of Wolbachia in D. melanogaster may confer a positive effect on the replication of exogenous nonpathogenic bacteria, this effect is not reciprocal as it fails to stimulate the propagation of those endosymbionts in the fly. Previously, clean injury of wild-type flies or infection with the Gram-positive Micrococcus luteus or the Gram-negative E. carotovora stimulated Spiroplasma growth [37]; however, in our experiments we did not observe any changes in Spiroplasma cell numbers in flies injected with the bacteria or PBS. Therefore, we conclude that distinct types of bacterial infections can differentially influence the titers of certain endosymbionts in D. melanogaster flies.

Our current results show that Wolbachia endosymbionts in combination with Spiroplasma significantly induce the activation of Imd signaling, but not Toll and JNK signaling, in D. melanogaster upon injection with $P$. luminescens bacteria. Activation of the Imd pathway in flies carrying Wolbachia and Spiroplasma upon infection with P. luminescens, but not in flies containing Wolbachia only or no endosymbionts suggests that the presence of both endosymbiotic bacteria is essential to trigger Imd signaling in response to the pathogen. Interestingly, previous studies have shown lack of Imd pathway activation in flies containing Spiroplasma only upon infection with the Gram-negative bacteria E. carotovora [37], or Wolbachia only upon infection with three Gram-negative bacterial pathogens [35]. We speculate that Imd upregulation in flies carrying both Wolbachia and Spiroplasma in response to P. luminescens infection is probably a distinct effect to this pathogen and possibly to other insect-specific pathogenic bacteria. The molecular basis of this effect is currently unclear and will be a subject of our future research. In addition, we have previously observed low levels of Defensin mRNA in $P$. luminescens infected flies [52], which is in agreement with the inability of Gram-negative bacteria containing DAP-type peptidoglycan to induce Toll signaling in $D$. melanogaster [46]. Here we were curious to know whether the presence of endosymbionts could alter the transcriptional levels of Defensin that is partially regulated by the Toll pathway. Our current findings confirm our previous results that Defensin is transcribed at low levels upon infection with P. luminescens [52], and additionally show that the presence of Wolbachia alone or together with Spiroplasma bacteria does not affect Toll signaling in response to this pathogen. Up-regulation of Defensin by E. coli in flies containing both Wolbachia and Spiroplasma but not in those containing either Wolbachia only or no endosymbiotic bacteria is an unexpected yet intriguing result, because it suggests that Spiroplasma endosymbionts that lack a cell wall and the molecular patterns that trigger immune pathway activation are somehow able to induce Toll signaling upon challenge with nonpathogenic bacteria. The molecular processes that lead to Toll activation in Spiroplasma-containing flies are currently unknown and beg for further investigation. In contrast to our findings, previous studies have failed to show activation of a systemic immune response by Spiroplasma endosymbionts in infected or uninfected $D$. melanogaster adult flies $[37,53,54]$. We further suspect that $P$. luminescens infection in combination with the occurrence of both endosymbionts in these flies is likely to increase stress conditions that could lead to early overactivation of Jak/Stat signaling, although induction of this pathway in $\mathrm{W}+\mathrm{S}+$ flies does not alter pathogen load and the survival response of the flies to the pathogen.

We then examined the potential effect of endosymbionts on the D. melanogaster cellular immune response, which mainly involves the activity of circulating macrophage-like insect blood cells called hemocytes that engulf microbes through phagocytosis [55]. We did not perform infections with stained $P$. luminescens cells because this pathogen has been shown previously to interfere with the cellular immune response by disrupting phagocytosis and other hemocyte-related immune functions such as hemocyte aggregation, nodulation and encapsulation [41]. We found no evidence that Wolbachia endosymbionts alone or together with Spiroplasma affect phagocytosis of E. coli particles in D. melanogaster flies. Because Wolbachia are intracellular bacteria that are found in various tissues but mainly occupy the reproductive organs of their hosts $[13,19]$, it would be rather unlikely that these endosymbionts can interact with insect hemocytes to alter the phagocytic ability of their host. However, Spiroplasma endosymbionts are primarily found in the hemolymph [12], and although they could come into contact with phagocytic cells, their potential interaction does not seem to affect phagocytosis of inactive bacterial particles. It has also been shown earlier that genetic ablation of phagocytes in D. melanogaster adult flies does not reduce Spiroplasma titers in the hemolymph [37]. 
Future work will focus on the role of endosymbiotic bacteria in the immune response of $D$. melanogaster flies against infection by the mutualistic partner of $P$. luminescens bacteria, the parasitic nematode $H$. bacteriophora [39]. Interestingly, recent studies have shown that the mushroom-feeding flies $D$. neotestacea harboring Spiroplasma endosymbionts have increased tolerance to their natural nematode parasite Howardula aoronymphium [56], and that the number of worms decreases in flies carrying Spiroplasma, but not in those lacking the endosymbionts [57]. In addition, it will be of particular interest to test the participation of endosymbionts against entomopathogenic nematodes and their associated bacteria in D. melanogaster larvae, which have a distinct immune response compared to the adult fly $[58,59]$.

\section{Conclusions}

In this study we demonstrate that injection of the virulent entomopathogenic bacterium $P$. luminescens into D. melanogaster adult flies carrying Wolbachia endosymbionts alone or Wolbachia and Spiroplasma bacteria together can affect the transcriptional activation of certain immune-related genes and Wolbachia titers, but not pathogen load. However, infection of D. melanogaster flies carrying both endosymbionts with a non-pathogenic strain of $E$. coli can affect the transcriptional activation of AMP genes and bacterial burden, but not endosymbiont numbers. We further show that the presence of endosymbiotic bacteria in the fly does not alter phagocytosis of inactive bioparticles. Finally we find that changes in AMP gene transcription and bacterial load do not change the survival of $D$. melanogaster strains containing Wolbachia only or both endosymbiotic bacteria compared to those lacking the endosymbionts following infection with $P$. luminescens or E. coli.

\section{Abbreviations}

AMP: Antimicrobial peptide; ANOVA: Analysis of variance; CDNA: Complementary DNA; CFU: Colony forming units;

DEPC: Diethylpyrocarbonate; IJ: Infective juvenile; Imd: Immune deficiency; Jak/Stat: Janus kinase and signal transducer and activator of transcription; JNK: c-Jun N-terminal kinase; LB: Iuria-bertani; MAPK: Mitogen-activated protein kinase; NF-kB: Nuclear factor-kappa-B; PBS: Phosphate buffered saline; PCR: Polymerase chain reaction; qRT-PCR: Quantitative real-time PCR; TAE: Tris-acetate-EDTA; Tot: Turandot.

\section{Competing interests}

The authors declare that they have no competing interests.

\section{Authors' contributions}

US, SY, JAt, JAC, JJ and IE conceived and designed the experiments; US, SY, JAt, JAC, EK, KB and AK carried out the experiments; US, SY, JAt and JAC analyzed the data; IE, US and SY wrote the paper and JJ revised it. All authors read and approved the final version of the manuscript.

\section{Acknowledgements}

This research was supported by a GWU Facilitating Fund to loannis Eleftherianos and by a GWU Enosinian fund to JAC.

\section{Author details}

'Insect Infection and Immunity Lab, Department of Biological Sciences, Institute for Biomedical Sciences, The George Washington University, 5675 Science and Engineering Hall, 800 22nd Street NW, Washington D.C. 20052, USA. ${ }^{2}$ Department of Biology, University of Rochester, Rochester, NY 14627, USA.

Received: 3 August 2015 Accepted: 2 February 2016

Published online: 09 February 2016

\section{References}

1. Uvell H, Engström Y. A multilayered defense against infection: combinatorial control of insect immune genes. Trends Genet. 2007;23:342-9.

2. Buchon N, Silverman N, Cherry S. Immunity in Drosophila melanogasterfrom microbial recognition to whole-organism physiology. Nat Rev Immunol. 2014;14:796-810.

3. Ganesan S, Aggarwal K, Paquette N, Silverman N. NF-kB/Rel proteins and the humoral immune responses of Drosophila melanogaster. Curr Top Microbiol Immunol. 2011;349:25-60.

4. Marmaras VJ, Lampropoulou M. Regulators and signalling in insect haemocyte immunity. Cell Signal. 2009;21:186-95.

5. Eleftherianos I, Revenis C. Role and importance of phenoloxidase in insect hemostasis. J Innate Immun. 2011;3:28-33.

6. Kim SH, Lee WJ. Role of DUOX in gut inflammation: lessons from Drosophila model of gut-microbiota interactions. Front Cell Infect Microbiol. 2014;3:116.

7. Davies SA, Dow JA. Modulation of epithelial innate immunity by autocrine production of nitric oxide. Gen Comp Endocrinol. 2009;162:113-21.

8. Dionne MS, Schneider DS. Models of infectious diseases in the fruit fly Drosophila melanogaster. Dis Model Mech. 2008;1:43-9.

9. Valanne S. Functional genomic analysis of the Drosophila immune response. Dev Comp Immunol. 2014;42:93-101.

10. Su Q, Zhou X, Zhang Y. Symbiont-mediated functions in insect hosts. Commun Integr Biol. 2013;6:e23804

11. Hilgenboecker $K$, Hammerstein P, Schlattmann P, Telschow A, Werren JH. How many species are infected with Wolbachia?-A statistical analysis of current data. FEMS Microbiol Lett. 2008;281:215-20.

12. Haselkorn TS. The Spiroplasma heritable bacterial endosymbiont of Drosophila. Fly. 2010;4:80-7.

13. Werren JH, Baldo L, Clark ME. Wolbachia: master manipulators of invertebrate biology. Nat Rev Microbiol. 2008;6:741-51.

14. Saridaki A, Bourtzis K. Wolbachia: more than just a bug in insects genitals. Curr Opin Microbiol. 2010;13:67-72.

15. Regassa LB, Gasparich GE. Spiroplasmas: evolutionary relationships and biodiversity. Front Biosci. 2006;11:2983-3002.

16. Gross J, Bhattacharya D. Mitochondrial and plastid evolution in eukaryotes: an outsiders' perspective. Nat Rev Genet. 2009;10:495-505.

17. Douglas AE. Lessons from studying insect symbioses. Cell Host Microbe. 2011;10:359-67.

18. Weiss BL, Maltz M, Aksoy S. Obligate symbionts activate immune system development in the tsetse fly. J Immunol. 2012;188:3395-403.

19. Eleftherianos I, Atri J, Accetta J, Castillo JC. Endosymbiotic bacteria in insects: guardians of the immune system? Front Physiol. 2013;4:46.

20. Brownlie JC, Johnson KN. Symbiont-mediated protection in insect hosts. Trends Microbiol. 2009;17:348-54.

21. McGraw EA, O'Neill SL. Wolbachia pipientis: intracellular infection and pathogenesis in Drosophila. Curr Opin Microbiol. 2004;7:67-70.

22. Bourtzis K, Pettigrew MM, O'Neill SL. Wolbachia neither induces nor suppresses transcripts encoding antimicrobial peptides. Insect Mol Biol. 2000;9:635-9.

23. Teixeira $L$, Ferreira A, Ashburner M. The bacterial symbiont Wolbachia induces resistance to RNA viral infections in Drosophila melanogaster. PLoS Biol. 2008;6:e2.

24. Hedges LM, Brownlie JC, O'Neill SL, Johnson KN. Wolbachia and virus protection in insects. Science. 2008;322:702.

25. Osborne SE, Leong YS, O'Neill SL, Johnson KN. Variation in antiviral protection mediated by different Wolbachia strains in Drosophila simulans. PLoS Pathog. 2009;5:e1000656.

26. Shaw AE, Veronesi E, Maurin G, Ftaich N, Guiqen F, Rixon F, Ratinier M, Mertens P, Carpenter S, Palmarini M, Terzian C, Arnaud F. Drosophila melanogaster as a model organism for bluetongue virus replication and tropism. J Virol. 2012:86:9015-24. 
27. Hedges LM, Yamada R, O'Neill SL, Johnson KM. The small interfering RNA pathway is not essential for Wolbachia-mediated antiviral protection in Drosophila melanogaster. Appl Environ Microbiol. 2012;78:67730-6776.

28. Chrostek E, Marialva MS, Esteves SS, Weinert LA, Martinez J, Jiggins FM, Teixeira L. Wolbachia variants induce differential protection to viruses in Drosophila melanogaster: a phenotypic and phylogenomic analysis. PLoS Genet. 2013;9:e1003896.

29. Chrostek E, Marialva MS, Yamada R, O'Neill SL, Teixeira L. High anti-viral protection without immune upregulation after interspecies Wolbachia transfer. PLoS One. 2014;9:e99025.

30. Martinez J, Longdon B, Bauer S, Chan YS, Miller WJ, Bourtzis K, Teixeira L, Jiggins FM. Symbionts commonly provide broad spectrum resistance to viruses in insects: a comparative analysis of Wolbachia strains. PLoS Pathog. 2014;10:e1004369.

31. Ferreira ÁG, Naylor H, Esteves SS, Pais IS, Martins NE, Teixeira L. The Tolldorsal pathway is required for resistance to viral oral infection in Drosophila. PLoS Pathog. 2014;10:e1004507.

32. Fytrou A, Schofield PG, Kraaijeveld AR, Hubbard SF. Wolbachia infection suppresses both host defence and parasitoid counter-defence. Proc Biol Sci. 2006;273:791-6.

33. Xie J, Vilchez I, Mateos M. Spiroplasma bacteria enhance survival of Drosophila hydei attacked by the parasitic wasp Leptopilina heterotoma. PLoS One. 2010;5:e12149.

34. Xie J, Tiner B, Vilchez I, Mateos M. Effect of the Drosophila endosymbiont Spiroplasma on parasitoid wasp development and on the reproductive fitness of wasp-attacked fly survivors. Evol Ecol. 2011;25:1065-79.

35. Wong ZS, Hedges LM, Brownlie JC, Johnson KN. Wolbachia-mediated antibacterial protection and immune gene regulation in Drosophila. PLoS One. 2011;6:e25430.

36. Rottschaefer SM, Lazzaro BP. No effect of Wolbachia on resistance to intracellular infection by pathogenic bacteria in Drosophila melanogaster. PLoS One. 2012;7:e40500

37. Herren JK, Lemaitre B. Spiroplasma and host immunity: activation of humoral immune responses increases endosymbiont load and susceptibility to certain Gram-negative bacterial pathogens in Drosophila melanogaster. Cell Microbiol. 2011:13:1385-96.

38. Waterfield NR, Ciche T, Clarke D. Photorhabdus and a host of hosts. Ann Rev Microbiol. 2009;63:557-74.

39. Ciche T. The biology and genome of Heterorhabditis bacteriophora. WormBook. 2007. doi:10.1895/wormbook.1.135.1.

40. Ffrench-Constant RH, Dowling A, Waterfield NR. Insecticidal toxins from Photorhabdus bacteria and their potential use in agriculture. Toxicon. 2007:49:436-51.

41. Eleftherianos I, Ffrench-Constant RH, Clarke DJ, Dowling AJ, Reynolds SE. Dissecting the immune response to the entomopathogen Photorhabdus. Trends Microbiol. 2010;18:552-60.

42. Ventura IM, Martins AB, Lyra ML, Andrade CA, Carvalho KA, Klaczko LB. Spiroplasma in Drosophila melanogaster populations: prevalence, malekilling, molecular identification, and no association with Wolbachia. Microb Ecol. 2012;64:794-801.

43. Newton IL, Sheehan KB. Passage of Wolbachia pipientis through mutant Drosophila melanogaster induces phenotypic and genomic changes. Appl Environ Microbiol. 2015;81:1032-7.

44. Kageyama D, Anbutsu H, Watada M, Hosokawa T, Shimada M, Fukatsu T. Prevalence of a non-male-killing spiroplasma in natural populations of Drosophila hydei. Appl Environ Microbiol. 2006;72:6667-73.

45. Rugjee KN, Roy Chaudhury S, Al-Jubran K, Ramanathan P, Matina T, Wen J, Brogna S. Fluorescent protein tagging confirms the presence of ribosomal proteins at Drosophila polytene chromosomes. PeerJ. 2013;1:e15.

46. Tanji T, Hu X, Weber AN, Ip YT. Toll and IMD pathways synergistically activate an innate immune response in Drosophila melanogaster. Mol Cell Biol. 2007;27:4578-88.

47. Kaneko T, Silverman N. Bacterial recognition and signalling by the Drosophila IMD pathway. Cell Microbiol. 2014;7:461-9.

48. Imler JL, Bulet P. Antimicrobial peptides in Drosophila: structures, activities and gene regulation. Chem Immunol Allergy. 2005;86:1-21.

49. Brun S, Vidal S, Spellman P, Takahashi K, Tricoire H, Lemaitre B. The MAPKKK Mekk1 regulates the expression of Turandot stress genes in response to septic injury in Drosophila. Genes Cells. 2006;11:397-407.
50. McEwen DG, Peifer M. Puckered, a Drosophila MAPK phosphatase, ensures cell viability by antagonizing JNK-induced apoptosis. Development. 2005; 132:3935-46

51. Lemaitre B, Hoffmann J. The host defense of Drosophila melanogaster. Annu Rev Immunol. 2007;25:697-743.

52. Castillo JC, Shokal U, Eleftherianos I, Castillo JC, Shokal U, Eleftherianos I. Immune gene transcription in Drosophila adult flies infected by entomopathogenic nematodes and their mutualistic bacteria. J Insect Physiol. 2012;59:179-85.

53. Hurst GD, Anbutsu H, Kutsukake M, Fukatsu T. Hidden from the host: Spiroplasma bacteria infecting Drosophila do not cause an immune response, but are suppressed by ectopic immune activation. Insect Mol Biol. 2003;12:93-7.

54. Anbutsu H, Fukatsu T. Evasion, suppression and tolerance of Drosophila innate immunity by a male-killing Spiroplasma endosymbiont. Insect $\mathrm{Mol}$ Biol. 2010;19:481-8.

55. Vlisidou I, Wood W. Drosophila blood cells and their role in immune responses. FEBS J. 2015;282:1368-82.

56. Jaenike J, Unckless R, Cockburn SN, Boelio LM, Perlman SJ. Adaptation via symbiosis: recent spread of a Drosophila defensive symbiont. Science. 2010;329:212-5.

57. Jaenike J, Brekke TD. Defensive endosymbionts: a cryptic trophic level in community ecology. Ecol Lett. 2011;14:150-5.

58. Fellous S, Lazzaro BP. Larval food quality affects adult (but not larval) immune gene expression independent of effects on general condition. Mol Ecol. 2010:19:1462-8.

59. Fellous S, Lazzaro BP. Potential for evolutionary coupling and decoupling of larval and adult immune gene expression. Mol Ecol. 2010;19:1558-67.

\section{Submit your next manuscript to BioMed Central and we will help you at every step:}

- We accept pre-submission inquiries

- Our selector tool helps you to find the most relevant journal

- We provide round the clock customer support

- Convenient online submission

- Thorough peer review

- Inclusion in PubMed and all major indexing services

- Maximum visibility for your research

Submit your manuscript at www.biomedcentral.com/submit 